\title{
A Conceptual Approach to Green Human Resource Management and Corporate Environmental Responsibility in the Hospitality Industry*
}

\author{
Paudel TULSI ${ }^{1}$, Yunho $\mathrm{JI}^{2}$ \\ Received: June 02, 2019 Revised: November 01, 2019 Accepted: November 15, 2019
}

\begin{abstract}
Substantial growth in the economy and extensive use of natural resources has become a major issue in the modern world. Organizations have started to worry about the environment and are beginning to invest in and practice green strategies. Companies should be responsible for the environment and use sustainable methods to run their businesses. The main purpose of this study is to explore the conceptual approach to Green Human Resource Management (GHRM) practices and Corporate Environmental Responsibility (CER) in the hospitality industry. The theoretical framework of GHRM practices such as green recruitment, green selection, green training and development, green performance appraisal, green reward and compensation, and corporate environmental responsibility have been comprehensively studied for this purpose. Green Human Resource Management in the hospitality sector is a less studied and rarely implemented phenomenon. The integration of GHRM and CER along with green competitive advantage and green supply chain management in hospitality is new concept in hospitality industry. Study suggests that Corporate environmental responsibility (CER) and Green Human Resource Management (GHRM) have a significant role in the hospitality industry. However, for sustainable development of tourism and hospitality, this concept should be capitalized with necessary research and development.
\end{abstract}

Keywords : Green Human Resource Management, Green Supply Chain Management, Green Competitive Advantage, Corporate Environmental Responsibility, Green Organizations

JEL Classification Code : F64, L83, M14, O15, Z32

\section{Introduction}

The impacts of ecological calamities and an unnatural weather change is increasing over time. The world's atmosphere has changed significantly in the previous decades and is expected keep changing at a similar or higher

\footnotetext{
* This study was supported by 2019 Research Grant from Kangwon National University.

1 First Author, Ph.D. Candidate, Department of Tourism Administration, Kangwon National University, Republic of Korea. Email: tulsi101@gmail.com

2 Corresponding Author, Assistant Professor, Department of Tourism Administration, Kangwon National University, Republic of Korea. [Postal Address: 192-1, Hyoja-Dong, Chuncheon Kangwon-Province 200-70, Republic of Korea]. Email: yunho.ji@kangwon.ac.kr

(c) Copyright: Korean Distribution Science Association (KODISA)

This is an Open Access article distributed under the terms of the Creative Commons Attribution Non-Commercial License (http://Creativecommons.org/licenses/by-nc/4.0/) which permits unrestricted noncommercial use, distribution, and reproduction in any medium, provided the original work is properly cited.
}

rate in the future. One of the primary reasons behind this is the increase in economic activities and the consequent degradation of the environment (Alvarado \& Toledo, 2017). Worldwide consensus has emerged about proactive environmental management towards sustainability. Organizations globally are anticipated to take responsibility for environmental management (Rondinelli \& Berry, 2000).

Business activities have simultaneous effect on humans and nature. Thus, private and public organizations are increasingly looking for solutions for these environmental issues. Governments, private and public companies are facing challenges in greening opportunities. Human Resource Management (HRM) practices have been relatively slow in addressing environmental issues (Jackson et al., 2011).

Researchers and practitioners have already begun integrating HRM practices with environmental management (Renwick et al., 2013).This integration of employee management for environmental conservation is known as 
Green Human Resource Management (GHRM) (Renwick et al., 2013). The objective of GHRM is to enhance the environmental performance of organizations comprising of employee engagement and environmental commitment (Jackson et al., 2011). Human resources (HR) should align with environmental management to implement and maintain environmental management systems (Govindarajulu \& Daily, 2004).

Few research works have addressed employee management that encourages employees to improve the environmental performance of the hospitality organization (Paillé et al., 2014). Most of the theoretical and empirical research on GHRM were carried out in developed western cultures (Jabbour \& de Sousa Jabbour, 2016). There are still discussions and uncertainty about GHRM practices to improve environmental performance. Also, human contributions to the environmental performance of hospitality organizations are often neglected in research.

The hospitality sector plays an important role with a significant contribution to the world's economy. The tourism industry contributed to $10.4 \%$ of the world's GDP in the global service sector and generated 319 million jobs, or $10 \%$ of total employment in 2018 (WTTC,2019). However, tourism industry is one of the largest consumers of environmental resources in the world. The hospitality industry accounts to nearly 5\% of global $\mathrm{CO} 2$ emissions (UN World Tourism Organization, 2017). Lee and Kwang(2013) argued about the importance of greening of the tourism and hospitality industry for green grown and sustainability.

Research studies on greening the organization through the relationship between HRM and Environment Management (EM) began in the 1990s. Wehrmeyer (1996) published a book entitled "Greening people: human resources and environmental management". With increasing numbers of similar studies, it has become more apparent that organizations need HRM practices to implement greening initiatives (Sudin, 2011). Studies that discussed the positive effects of HRM on the Environment Performance (EP) of companies have reinforced green initiatives (Schuler \& Jackson, 2014). The introduction of the famous environmental management system, ISO14001 was another major factor that fueled the expansion of such studies (Jabbour \& Jabbour 2016). Greening of human factors could have been more productive with a competitive advantage (Cherian \& Jacob, 2012). Organizations that do not have a comprehensive GHRM program will have potential limitations on their EP's effectiveness (Renwick et al., 2013). In large organizations, although they try to influence and increase the environmental behavior of employees, there is a visible difference in environmental policies and actual employee behavior patterns.

The definition of Corporate Social Responsibility (CSR) according to World Business Council for Sustainable Development (WBCSD, 2000) is "the continuing commitment by businesses to behave ethically and contribute to economic development while improving the quality of life of the workforce and their families as well as of the local community and society at large". Activities with an internal dimension of CSR incorporates with employees, stakeholders, consumers, and corporations (European Commission, 2001). The external dimension deals with local communities, health rights, and global environmental concerns.

Researchers had insights into several dimensions of CSR. However CER and GHRM is less researched in hospitality industry. The widely researched external dimension of CSR is not concerned with HRM which and its greening consequences. Particularly, in the hospitality sector, the external dimension of CSR is being researched but lacks integration with human resource management. Though, diverse existing literature deals with the topic of GHRM and CER there is still confusion with adequate utilization of the concept. The main purpose of this article is to find the conceptual approach of GHRM in the hospitality industry with a comprehensive review of literatures. This study will contribute to the research gaps of GHRM and CER in the context of the hospitality industry.

\section{Literature Review}

\subsection{Green Human Resource Management}

Employees at all levels of an organization need explicitly defined GHRM practices to improve the environmental performance of the organization. Green HRM practices can be used to encourage the responsible behavior of employees to preserve the environment (Cherian \& Jacob, 2012).

GHRM's notion is related to the HRM function as the main driver of green initiatives in an organization (Jabbour \& Jabbour, 2016). Sharma and Gupta (2015) defined GHRM as HRM practices to promote sustainable resource use which increases employee awareness and commitments towards environmental management issues. GHRM has supported the paradigmatic understanding of the ' triple bottom line ' concept; that is, GHRM involves practices aligned with the three pillars of environmental, social, and economic sustainability and provides the organization long-term benefits (Yusoff et al., 2015). O'Donohue and Torugsa (2016) studied the link between environmental management and organizational financial performance in the machinery and equipment manufacturing sector in Australia. They found that higher levels of GHRM practices are positively linked to increasing financial benefits on hospitality organization's overall financial performance. Similarly, GHRM is part of a broader corporate social responsibility program (Sathyapriya et al., 2013).

In this regard, people working for the organization are expected to raise awareness among HR managers about how to improve the hospitality organization's EP through human behavior (Shaikh 2010). Jabbar and Abid (2014) found that monetary and non-monetary rewards given to employees 
motivate them to play an active role in eco-initiatives. They also argued, employees are more willing to actively support greening practices when their immediate managers show such practices. Hence, involving employees in greener activities at every step of HRM practices is important for managers; once it becomes a daily activity, it will be treated as a culture (Jabbour et al., 2008). HRM support is necessary to manufacture products with a lower environmental impact (Govindarajulu \& Daily, 2004). This was also asserted by Jabbour and Santos (2008b), explaining higher EP outcome requires HRM practices that support the hospitality organization's entire implementation and maintenance of the Environmental Management System (EMS).

The latest studies illustrate the integration of environmental management (EM) and HRM to achieve EP (Jabbour \& Jabbour, 2016). Jabbour and Santos (2008a) highlighted the integration of HR factors such as green recruitment, green selection, green training, green performance assessment, reward systems, empowerment, and organizational culture management. The above list of GHRM practices are more tangible and can ensure that green issues are considered in the daily routine of employees (Jabbour and Jabbour 2016). Figure1 shows the GHRM process where main components, Green Recruitment, Green Selection, Green Training, Green Performance, Green Appraisal, Green Rewards, and Green Compensation are incorporated with other sub-components.

\subsection{GHRM Practices in the Hospitality Industry}

There are limited researches in the hospitality sector in the context of GHRM. However, some researchers did empirical studies in hotel industries. Yusoff et al. (2018) conducted an empirical study of GHRM and the environmental performance of Malaysian hotels. The authors found GHRM practices have a significant role in the environmental performance of hotel. Employees' involvement in environmental performance is significant and challenging (Chan \& Hawkins, 2010). Hotel organizations are particularly dependent on human resources so employee's creativity level may affect their flexibility in service delivery and innovative ideas (Kim, 2019). Furthermore, service quality influences costs and productivity which enhances the concept of green economy comprising renewable energy, energy efficiency, and waste management (Mukhtarova \& Zhidebekkyzy, 2015). Most of the studies regarding GHRM and CER are focused on the manufacturing sector. The GHRM practices in the hospitality industry are in the early stages and need more significance of research and investigation. The GHRM practices described in the following sections have mainly been conducted in the business enterprises. However, the implications of these practices would benefit the hospitality sector.

\subsubsection{Green Recruitment and Selection}

Hospitality Organizations should focus on the selection of employees who support and are interested in the environment (Renwick et al., 2013). To attract such talents, organizations should build their reputation as environmentally friendly and responsive to the environment (Guerci et al., 2016). The environmental sustainability agenda of hospitality organizations should reflect on their publications and activities (Arulrajah et al., 2015). To attract prospective applicants environmental sustainability-related intents play a vital role (Guerci et al., 2016). Green recruitment exhibits an understanding of green culture and environmental values of hospitality organizations through stretching out employees' environmental awareness, values, and trusts (Renwick et al., 2013; Jackson \& Seo, 2010).

Arulrajah et al. (2015) argued about the inclusion of environmental criteria in recruitment messages. Job analysis should focus on environmental aspects, green accomplishments and expectations from the future green employee (Renwick et al., 2013). Wehrmeyer (2017) recommended measures to environmental reporting and educating the newly appointed employee about environmental sustainability policies, values, and green goals of the organization. The questions should be designed with environment-related aspects (Razab et al.2015). Arulrajah et al. (2015) argued about improvements to protect the environment with integration of environmental task into duties and responsibilities. While shortlisting candidates who involved in green activities and who are committed to green initiatives should be given priority (Jabbour, 2013).

\subsubsection{Green Training and Development}

Environmental training is one of the primary methods through which HRM establish GHRM initiatives (Jabbour, 2013). Teixeira et al. (2012) investigated two constructs environmental training and environmental management in Brazilian organizations. According to Opatha and Arulrajah (2014), environmental training has the most significant impact on awareness which is responsible for the creation of green practice culture. Arulrajah et al. (2015) investigated the value of green education and training of employees such as the inclusion of social and environmental issues at all levels. It is important to consider training needs while design environmental training to get optimal environmental outputs (Cherian \& Jacob, 2012).

The study of Daily et al. (2012) in 220 manufacturing companies in Mexico discovered that, environmental training of employees is more effective than environmental empowerment. Environmental training and development strategy should include events, workshops, and sessions to facilitate employees to develop and acquire knowledge of Environmental Management (EM) (Prasad, 2013). Furthermore, Renwick et al. (2013) recommended green training and development produces green analysis of workspace, energy efficiency, waste management, recycling, and development of green personal skills. Zoogah (2011) 
also emphasized opportunities provide by organizations to engage employees in environmental problem-solving projects. For these particular aspects, job rotation principles should be used in green assignments as an essential part of training and career development plans for talented green managers (Wehrmeyer, 2017).

\subsubsection{Green Performance Management and} Appraisal

A performance management system (PMS) provides a platform to measure the desire of employees for environment performance (Ahmad, 2015). PMS ensures the efficacy of green management work throughout the time and looks after EM initiatives against any distortions (Jackson et al, 2011). Environmental Management Information System (EMIS) is useful tool to record flow of resources and green audits. To achieve better environmental performance firms should focus on enterprise-level metrics and evaluate resource acquisitions, and asset acquisitions (Arulrajah et al., 2015). Hospitality organizations developed corporate-wide environmental performance standards which are aligned with green information systems led to evaluate the green performance of their employees (Marcus \& Fremeth, 2009).

HRM should integrate environmental performance (EP) into a PMS by setting objectives and responsibilities. Monitoring environmental behaviors, and evaluating achievement of environmental objectives as green work rating is the key indicator of job performance (Kapil, 2015). The green work rating needs to be included in managers' and employees' appraisal documents (Renwick et al., 2013). Moreover, managers must provide regular comments to the employees or teams about their role in accomplishing environmental desires (Arulrajah et al., 2015). This feedback will help the workers to improve their knowledge, skills, and capability.

Sharing appraisal outcomes with employees on how nicely they're making progress toward environmental targets is crucial for employees' motivation, and increases their engagement in EM responsibilities (Govindarajulu and Daily, 2004). Kapil (2015) suggested that organizations can provide an online information system and audits to mark employees' EM score. Human resources departments should redesign the performance appraisal rating system which can rate employees on their behavioral and technical competencies related to environmental sustainability (Ahmad, 2015).

\subsubsection{Green Reward and Compensation}

A hospitality organization's greening goal can be achieved by rewarding employees for their commitment to environmental practices (Jabbour \& Jabbour, 2016). If the organization focuses on avoiding negative behaviors and encouraging eco-friendly behavior, EM could benefit from reward and compensation (Zoogah, 2011). Reward systems should be designed to reflect the commitment of management to EP while strengthening and motivating the pro-environmental behaviors of employees (Daily \& Huang, 2001). The commitment from management will foster employee engagement on environmentally responsible behavior which motivates eco-initiatives (Renwick et al, 2013). Calia et al. (2009) argued that reward programs increases motivation for the environmentally friendly behavior of employees. Moreover, they emphasize linking rewards with the results of greening projects within hospitality organizations.

Rewards may be based on monetary EM rewards (e.g. bonuses, cash, premiums), non-monetary EM rewards (e.g. sabbaticals, leave, gifts), recognition-based EM rewards (e.g. awards, dinners, advertising, external roles, daily praise), and positive EM rewards (e.g. feedback) (Opatha, 2013). Employees who are dedicated to achieving environmental goals and those in middle management who encourage their subordinates to adopt green practices should be rewarded (Arulrajah et al., 2015). Ramus (2001) illustrated the impact of rewards on the implementation of environmental practices. Also, hospitality organizations can access green reward management practices by linking green initiatives promotion/career gains or by providing incentives to encourage green recycling and waste management practices (Jabbar \& Abid, 2014). The green creativity and innovation of employees can be enhanced promoting them to share ideas behind green activities about their work (Ahmad, 2015).

This study, emphasizes the importance of GHRM practices in hospitality industry. The brief summary of works by various researchers to identify GHRM practices (Wehrmeyer, 1996; Renwick et al. 2008; Renwick et al., 2013; Jackson et al., 2011; Opatha, 2013; Randinelli \& Berry, 2000) are illustrated in Table 1 This will be helpful to develop measures and constructs of GHRM practice in future research.

Table 1 : Constructs and Measures of GHRM Practices

\begin{tabular}{|c|c|}
\hline GHRM Components & GHRM Measures \\
\hline $\begin{array}{l}\text { Green Recruitment } \\
\text { and Selection }\end{array}$ & $\begin{array}{l}\text { - } \quad \text { Indication of the environmental performance of communicating recruitment messages. } \\
\text { - } \quad \text { Reflecting the organization's environmental policies and strategies in its recruitment policy. } \\
\text { - } \quad \text { Expressing certain environmental values in the company's job advertisements. } \\
\text { - } \quad \text { Selecting applicants who are engaged as consumers in greening under their domain of private life. }\end{array}$ \\
\hline $\begin{array}{l}\text { Green Training and } \\
\text { Development }\end{array}$ & $\begin{array}{l}\text { - } \quad \text { Train environmental awareness among the workforce to produce green workspace analysis. } \\
\text { - } \quad \text { Providing proper greening knowledge and skills (to each employee through a greening-only training program). } \\
\text { - } \quad \text { Analysis and identification of employees' environmental training needs. } \\
\text { - } \quad \text { Implementing a serious and systematic training program given to all employees }\end{array}$ \\
\hline
\end{tabular}




\begin{tabular}{|c|c|}
\hline $\begin{array}{c}\text { Green Performance } \\
\text { appraisal }\end{array}$ & $\begin{array}{l}\text { - Incorporate environmental management objectives and targets with the organization's performance } \\
\text { - } \quad \text { Integluation system. } \\
\text { green criteria. } \\
\text { - Including a separate component for greening progress in the performance feedback interview. } \\
\text { - Introduce or formally evaluate all employees ' green work performance. }\end{array}$ \\
\hline $\begin{array}{l}\text { Green Reward and } \\
\text { Compensation }\end{array}$ & 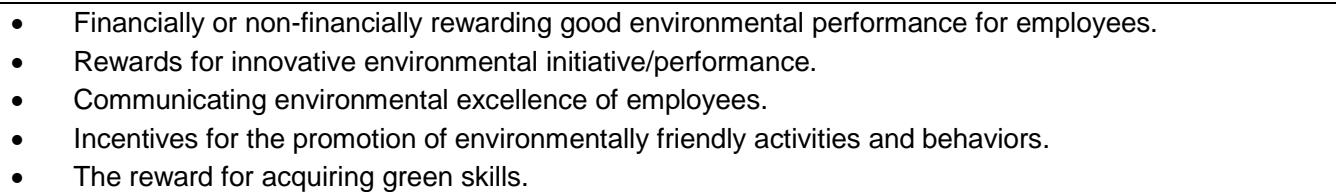 \\
\hline
\end{tabular}

\subsection{Corporate Environmental Responsibility}

The corporate social responsibility (CSR) concerned with social and environmental aspects is termed as customer environmental responsibility (CER) (Van Marrewijk, 2003). Freemans'1999 stakeholder CSR theory focuses on issues with human rights and global environment concerns and its activities related to human resources management practices. The Environmental corporate social responsibility (ECSR) fosters the idea of protection of the environment along with the operation of a business. The role of HRM to understand CSR is significant; moreover, both CSR and HRM are relevant to understand the relationship between employer and employees (Voegtlin \& Greenwood, 2016). Most companies are using their substantial resources to ensure CSR practices to make the company socially responsible allows researchers to investigate a variety of policies (Yoon $\&$ Lee, 2019). There has been research gap in theoretical linkage between CSR and HRM.

Hospitality organization's green management can be achieved through the application of innovation, reduction of waste, and social responsibility. Hospitality Organizations should pay attention to environmental issues because companies mostly focus on profits and outcomes causing distortions to the environment (Desjardins, 1998). Customer Environmental Responsibility (CER) is crucial to the sustainability of the local community. Companies should be responsible to prevent surrounding and overcome negative effects on the environment. Companies' environmental responsibilities influence corporate social image (Lee \& Lee, 2014). According to Orlitzky et al., (2011) managers of companies must determine the social responsibility of companies about the environment and ecology. For better financial performance organizations should consider environmental factors (Ma et al., 2017).

Excess use of resources and pollution increases importance of CER for sustainability of the community (Wang 2010). Greening the hospitality organization is a broad process of application of innovative ideas to achieve sustainability, minimize waste, and increase social responsibility with continuous development of environmental goals and fully integrated strategies (Haden et al., 2009). Implementation of Corporate Environmental Responsibility (CER) involves pollution avoidance, and product management focusing on the environmental effect of the product life cycle. Most leading hospitality organization think that corporate environmental responsibility is the duty to reduce the harm being done to the environment caused by the company's operation, products and amenities as well as to minimize the waste and emissions to achieve efficiency and productivity (Mazurkiewicz, 2004).

Numerous research and studies have argued about the corporate social responsibility of the hospitality and hotel industry. However, most studies have focused only on the environmental stakeholders. Employee and organization behavior on the other hand are less studied with regards to integration of environmental responsibility. The hospitality industry is itself a huge environment resource consumer and its responsibility towards the environment is also crucial. Moreover, the role of hospitality or tourism industry for the preservation of the environment is much expected in today's present time.

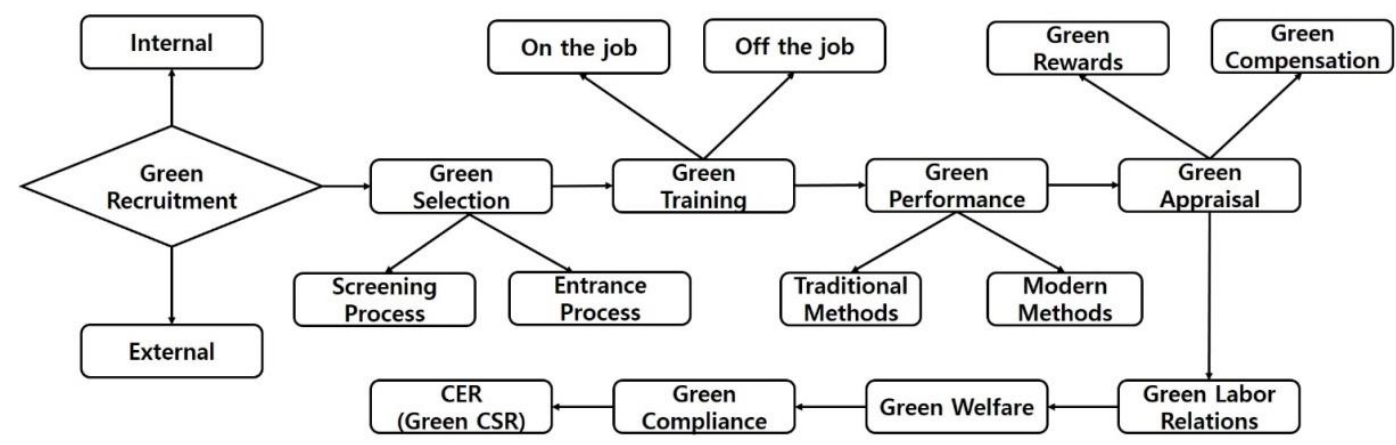

Figure 1: GHRM Process and CER (edited for GHRM from http//www.whatishumanresource.com) 


\section{Theoretical and Managerial Implications}

HRM plays the most significant role in managing the staff in any organization. The latest practices in HRM are focusing on greening the company with an extra responsibility on the HR executives for the implementation of Green HR policy. Previous literatures have confirmed that the placement of 'greening' as a main factor for the improvement of hospitality organizations 'environmental performance' (Stefan \& Paul, 2008). Premature GHRM has been a key idea for organization functioning and has been shown to have a significant impact on the outcome of the organization (Wagner, 2013). Green Performance is acknowledged as a necessity for the improvement of environmental education and green transformation leadership (Jabbour, 2013).

GHRM has significant scope for studies in leadership but has no backdrop in practice in academia. Therefore, research gap of environmental management and professional GHRM practices in the hospitality sector should be accompanied. In this respect, studies observing the global impact of GHRM systems rather than individual practices are especially helpful. Such research can assist hospitality organizations to decrease environmental damage and make the earth much cleaner and safer. Lack of studies in this sector with more aspects of green HRM make it absolutely essential that further studies be done.

The objective of GHRM should be to integrate greenery in daily routines and procedures regardless of whether it is the green team or executives. Environmental training should schedule and focus on organizational behavior that supports environmental commitment to attain proactive environmental management (Jabbour et al., 2010). The involvement of people in the company is crucial to achieving the green goal of an organization. Some previous studies discussed on inter-functional integration of green strategy and green operation. In hospitality sector, management usually separates human resources and environment. However, an important component for greening the organizations is regarded as the integration of human resources. Therefore, better knowledge of integration of environmental management and HRM can benefit the hospitality industry.

\section{Conclusions}

GHRM methods can provide mutual assistance and facilitate environmental performance once they are incorporated with GSCM methods. Sufficient training in the environment can enhance consciousness and build abilities. Likewise, the combination of green activities with compensation and benefits can encourage green conduct and develop a green organization. Green organizations not only help manage negative environmental impacts but also gain a favorable reputation, brand value, enhanced revenues, talent acquisition, devoted labor, greater efficiency for employees, motivation, and retention.

Hospitality organizations must look beyond their profitmaking objectives to create a sustainable economy and common value. Lieberwitz (2005) describes that organizations practice at the superficial level and their primary objective is to achieve profits. Mintzberg et al. (2002) indicated that a series of half-truths with the focus on profit is being carried out by many organizations. Most CER drivers such as public legislation, customer pressure, customer attraction, and risk control are taken outside the organization. Therefore the status of a genuinely green organization is hard to achieve.

It is also essential to concentrate internally, involve staff and change policies and procedures in the context of effective CER. For such inner changes GHRM plays a significant role. Greening of organizations by connecting GHRM procedures (such as green climate, recruiting, workforce, environmental training, performance management system, compensation, and benefit) should be clearly stated to the employees. It also creates a solid system for the pro-environmental purpose, ready to take the required adjustments into account. Similarly, GSCM can contribute through green product growth and green packaging by allowing inner modifications. The Greening of the organization assist to build shared value and the competitive advantage in the current situation when depletion of funds and increased environmental hazards are of major concern. The integration between the four fields (GHRM, GSCM, and CER), can generate synergies that lead to viable development throughout the organization.

Finally, we can conclude that GHRM has a significant scope in the hospitality industry. Lack of research and studies can be treated as an opportunity for new researchers. The earth is our home and should be conserved thoroughly. Organizations with less damage to the environment lead us to a sustainable and ecological era. The hospitality industry should step up for and help create environmental friendly performances. GHRM with integration of CER is a convenient tool for sustainability for hospitality industry. However, more research is required to accommodate GHRM and CER within the industry. This comprehensive study will be beneficial for top management and HR policymakers for the greening of hospitality organizations. This study did not take consideration of empirical analysis which comprises limitations of this study. Therefore strong empirical evidence will be the scope for future research indeed.

\section{References}

Ahmad, S. (2015). Green human resource management: Policies and practices. Cogent Business \& Management, 2(1), 1030817.

Alvarado, R., \& Toledo, E. (2017). Environmental degradation and economic growth: Evidence for a developing country. Environment, Development and Sustainability, 19(4), 1205-1218. 
Arulrajah, A. A., Opatha, H. H. D. N. P., \& Nawaratne, N. N. J. (2015). Green human resource management practices: A review. Sri Lankan Journal of Human Resource Management, 5(1), 1-16.

Calia, R. C., Guerrini, F. M., \& de Castro, M. (2009). The impact of Six Sigma in the performance of a Pollution Prevention program. Journal of Cleaner Production, 17(15), 1303-1310.

Chan, E. S., \& Hawkins, R. (2010). Attitude towards EMSs in an international hotel: An exploratory case study. International Journal of Hospitality Management, 29(4), 641-651.

Cherian, J., \& Jacob, J. (2012). A study of green HR practices and its effective implementation in the organization: A review. International Journal of Business and Management, 7(21), 25-33.

Daily, B. F., \& Huang, S. C. (2001). Achieving sustainability through attention to human resource factors in environmental management. International Journal of Operations \& Production Management, 21(12), 15391552.

Daily, B. F., Bishop, J. W., \& Massoud, J. A. (2012). The role of training and empowerment in environmental performance: A study of the Mexican maquiladora industry. International Journal of Operations \& Production Management, 32(5), 631-647.

DesJardins, J. (1998). Corporate environmental responsibility. Journal of Business Ethics, 17(8), 825838.

European Commission. (2001). Promoting a European framework for corporate social responsibility. Green Paper. http://europe.eu.int/comm/employment_social/socdial/csr/csr2002_en.pdf.

Freeman, R. E. (1999). Divergent stakeholder theory. Academy of Management Review, 24(2), 233-236.

Govindarajulu, N., \& Daily, B. F. (2004). Motivating employees for environmental improvement. Industrial Management \& Data Systems, 104(4), 364-372.

Guerci, M., Montanari, F., Scapolan, A., \& Epifanio, A. (2016). Green and nongreen recruitment practices for attracting job applicants: Exploring independent and interactive effects. The International Journal of Human Resource Management, 27(2), 129-150.

Jabbar, M. H., \& Abid, M. (2014). GHRM: Motivating employees towards organizational environmental performance. MAGNT Research Report, 2(4), 267-278.

Jabbour, C. J. C. (2013). Environmental training in organizations: From a literature review to a framework for future research. Resources, Conservation and Recycling, 74(1), 144-155.

Jabbour, C. J. C., \& de Sousa Jabbour, A. B. L. (2016). Green human resource management and green supply chain management: Linking two emerging agendas. Journal of Cleaner Production, 112(3), 1824-1833.

Jabbour, C. J. C., \& Santos, F. C. A. (2008a). Relationships between human resource dimensions and environmental management in companies: Proposal of a model. Journal of Cleaner Production, 16(1), 51-58.

Jabbour, C. J. C., \& Santos, F. C. A. (2008b). The central role of human resource management in the search for sustainable organizations. The International Journal of Human Resource Management, 19(12), 2133-2154.

Jabbour, C. J. C., Santos, F. C. A., \& Nagano, M. S. (2008). Environmental management system and human resource practices: Is there a link between them in four Brazilian companies?. Journal of Cleaner Production, 16(17), 1922-1925.

Jabbour, C. J. C., Teixeira, A. A., de Oliveira, J. H. C., \& Soubihia, D. F. (2010). Managing environmental training in organizations: Theoretical review and proposal of a model. Management of Environmental Quality: An International Journal, 21(6), 830-844.

Jackson, S. E., \& Seo, J. (2010). The greening of strategic HRM scholarship. Organization Management Journal, 7(4), 278-290.

Jackson, S. E., Renwick, D. W., Jabbour, C. J., \& MullerCamen, M. (2011). State-of-the-art and future directions for green human resource management: Introduction to the special issue. German Journal of Human Resource Management, 25(2), 99-116.

Kapil, K. (2015). GREEN HRM: TRENDS \& PROSPECTS. International Journal of Management Research, 3(1), 43-55.

Kim, J.-E. (2019). The impact of creative role identity and creative self-efficacy on employee creativity in the hotel business. The Journal of Asian Finance, Economics, and Business (JAFEB), 6(2), 123-133.

Lee, J. W., \& Kwag, M. (2013). Green growth and sustainability: The role of tourism, travel, and hospitality service industry in Korea. Journal of Distribution Science, 11(7), 15-22.

Lee, D. G., \& Lee, M. J. (2014). The effect of corporate social responsibility on corporate image and corporate performance. Journal of Distribution Science, 12(9), 101-112.

Lieberwitz, R. L. (2005). The corporatization of academic research: Whose interests are served. Akron Law Review, 38(4), 759-770.

Ma, J. H., Choi, S. B., \& Ahn, Y. H. (2017). The impact of eco-friendly management on product quality, financial performance, and environmental performance. Journal of Distribution Science, 15(5), 17-28.

Marcus, A., \& Fremth, A. R. (2009). Green management matters regardless. Academy of Management Perspectives, 23(3), 17-26.

Mazurkiewicz, P. (2004). Corporate environmental responsibility: Is a common CSR framework possible. World Bank, 2, 1-18.

Mintzberg, H., Simons, R., \& Basu, K. (2002). Beyond selfishness. MIT Sloan Management Review, 44(1), $67-$ 74.

Morgeson, F. P., Aguinis, H., Waldman, D. A., \& Siegel, D. S. (2013). Extending corporate social responsibility 
research to the human resource management and organizational behavior domains: A look to the future. Personnel Psychology, 66(4), 805-824.

Mukhtarova, K. S., \& Zhidebekkyzy, A. (2016). Development of green economy via commercialization of green technologies: Experience of Kazakhstan. International Conference on Business and Economics, 13, 363-365.

O'Donohue, W., \& Torugsa, N. (2016). The moderating effect of 'green' HRM on the association between proactive environmental management and financial performance in small firms. The International Journal of Human Resource Management, 27(2), 239-261.

Opatha, H. H. D. N. P. (2013). Green human resource management: A simplified introduction. Proceedings of the HR Dialogue, 1(1), 12-21.

Opatha, H. H. P., \& Arulrajah, A. A. (2014). Green human resource management: Simplified general reflections. International Business Research, 7(8), 101-112.

Orlitzky, M., Siegel, D. S., \& Waldman, D. A. (2011). Strategic corporate social responsibility and environmental sustainability. Business \& Society, 50(1), 6-27.

Paillé, P., Chen, Y., Boiral, O., \& Jin, J. (2014). The impact of human resource management on environmental performance: An employee-level study. Journal of Business Ethics, 121(3), 451-466.

Pane Haden, S. S., Oyler, J. D., \& Humphreys, J. H. (2009). Historical, practical, and theoretical perspectives on green management: An exploratory analysis. Management Decision, 47(7), 1041-1055.

Prasad, R. S. (2013). Green HRM-partner in sustainable competitive growth. Journal of Management Sciences and Technology, 1(1), 15-18.

Ramus, C. A. (2001). Organizational support for employees: Encouraging creative ideas for environmental sustainability. California Management Review, 43(3), 85105.

Razab, M. F., Udin, Z. M., \& Osman, W. N. (2015). Understanding the role of GHRM towards environmental performance. Journal of Global Business and Social Entrepreneurship (GBSE), 1(2), 118-125.

Renwick, D. W., Redman, T., \& Maguire, S. (2013). Green human resource management: A review and research agenda. International Journal of Management Reviews, 15(1), 1-14.

Renwick, D., Redman, T., \& Maguire, S. (2008). Green HRM: A review, process model, and research agenda. University of Sheffield Management School Discussion Paper, 1, 1-46.

Rondinelli, D. A., \& Berry, M. A. (2000). Environmental citizenship in multinational corporations: Social responsibility and sustainable development. European Management Journal, 18(1), 70-84.

Sathyapriya, J., Kanimozhi, R., \& Adhilakshmi, V. (2013). Green HRM-Delivering high-performance HR systems. International Journal of Marketing and Human Resource
Management, 4(2), 19-25.

Scarbrough, H. (2000). The HR implications of supply chain relationships. Human Resource Management Journal, 10(1), 5-17.

Schuler, R., \& Jackson, S. E. (2014). Human resource management and organizational effectiveness: Yesterday and today. Journal of Organizational Effectiveness: People and Performance, 1(1), 35-55.

Shaikh, M. (2010). Green HRM: A requirement of the $21 \mathrm{st}$ century. Journal of Research in Commerce and Management, 1(10), 122-127.

Sharma, S., \& Gupta, N. (2015). Green HRM: An innovative approach to environmental sustainability. Proceeding of Twelfth AIMS International Conference on Management, 825-830.

Stefan, A., \& Paul, L. (2008). Does it pay to be green? A systematic overview. Academy of Management Perspectives, 22(4), 45-62.

Sudin, S. (2011). Fairness of and satisfaction with the performance appraisal process. Journal of Global Management, 2(1), 66-83.

Teixeira, A. A., Jabbour, C. J. C., \& de Sousa Jabbour, A. B. L. (2012). Relationship between green management and environmental training in companies located in Brazil: A theoretical framework and case studies. International Journal of Production Economics, 140(1), 318-329.

United Nations World Tourism Organization. (2017). UNWTO Tourism Highlights 2017. World Tourism Organizations,

http://www2.unwto.org/publication/unwto-tourismhighlights-2017-edition-0.

Van Marrewijk, M. (2003). Concepts and definitions of CSR and corporate sustainability: Between agency and communion. Journal of Business Ethics, 44(2-3), 95-105.

Voegtlin, C., \& Greenwood, M. (2016). Corporate social responsibility and human resource management: A systematic review and conceptual analysis. Human Resource Management Review, 26(3), 181-197.

Wagner, M. (2013). 'Green' human resource benefits: Do they matter as determinants of environmental management system implementation?. Journal of Business Ethics, 114(3), 443-456.

Wang, H. (2010). Factor analysis of corporate environmental responsibility. Environment, Development and Sustainability, 12(4), 481-490.

World Business Council for Sustainable Development. (2000). Corporate social responsibility, meeting changing expectations. Geneva, Switzerland.

Wehrmeyer, W. (1996). Green policies can help to bear fruit. People Management, 2(4), 38-40.

Wehrmeyer, W. (2017). Greening people: Human resources and environmental management. Routledge.

World Travel \& Tourism Council. (2019). Travel \& Tourism Economic Impact 2019 - March 2019, Available: https://www.wttc.org/publications/

Yoon, B., Lee, J. H., Rahman, M. M., Meah, M. R., Chaudhory, N. U., Saima, F. N., ... \& Luchaninova, A. 
(2019). Corporate social responsibility and information asymmetry in the Korean market: Implications of chaebol affiliates. The Journal of Asian Finance, Economics, and Business (JAFEB), 6(1), 21-31.

Yusoff, Y. M., Nejati, M., Kee, D. M. H., \& Amran, A. (2018). Linking green human resource management practices to environmental performance in the hotel industry. Global Business Review, 21(3), 1-18.

Yusoff, Y. M., Ramayah, T., \& Othman, N. Z. (2015). Why examining adoption factors, $\mathrm{HR}$ role and attitude towards using E-HRM is the start-off in determining the successfulness of green HRM. Journal of Advanced Management Science, 3(4), 337-343.

Zoogah, D. B. (2011). The dynamics of green HRM behaviors: A cognitive social information processing approach. German Journal of Human Resource Management, 25(2), 117-139. 